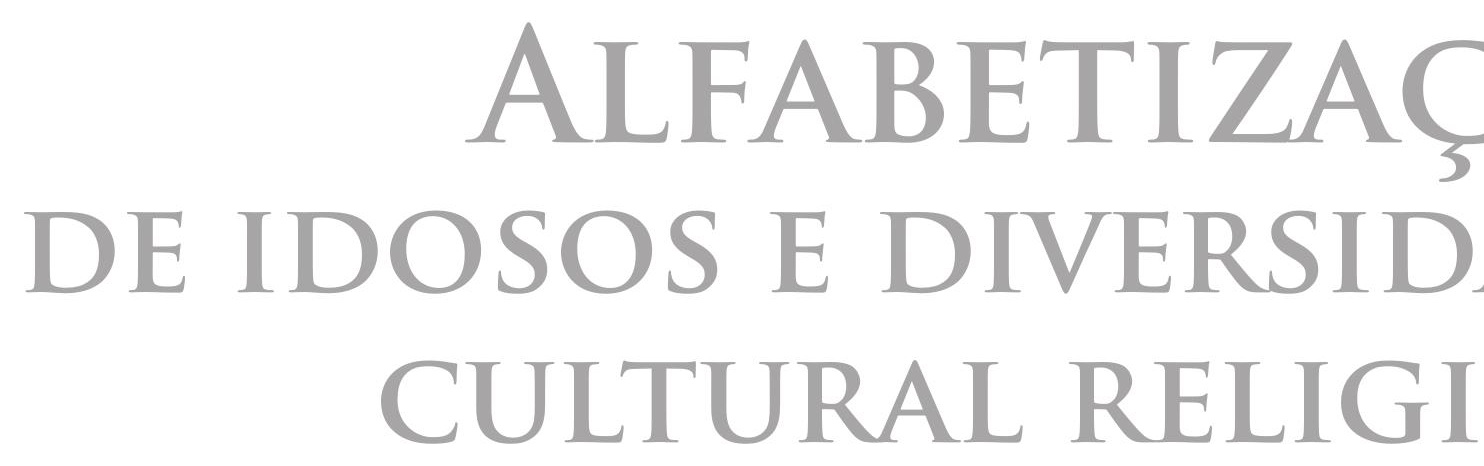




\section{ALFABETIZAÇÃO DE IDOSOS E DIVERSIDADE CULTURAL RELIGIOSA}




\title{
ALFABETIZAÇÃO DE IDOSOS E DIVERSIDADE CULTURAL RELIGIOSA
}

\section{Resumo}

Trata-se de uma pesquisa qualitativa de cunho fenomenológico realizada com 05 idosos em processo de alfabetização que procurou identificar práticas curriculares exitosas, vinculadas ao trabalho pedagógico que considere a Diversidade Religiosa no desenvolvimento da oralidade, da escrita e da leitura. O trabalho reafirma a importância da temática Diversidade Religiosa em todos os componentes curriculares, níveis e modalidades da Educação Básica.

Palavras-chaves: Alfabetização de idosos, Diversidade Religiosa, Leitura e escrita.

\section{LITERACY OF THE ELDERLY AND RELIGIOUS CULTURAL DIVERSITY}

\begin{abstract}
This is a qualitative research carried out with 05 elderly people in a literacy process that sought to identify successful curricular practices, linked to the pedagogical work that considers Religious Diversity in the development of orality, writing and reading. This paper reaffirms the importance of the theme Religious Diversity in all curricular components, levels and modalities of Basic Education.
\end{abstract}

Keywords: Elderly literacy, Religious Diversity, reading and writing 


\section{ALFABETIZACIÓN DE ANCIANOS YDIVERSIDAD CULTURAL RELIGIOSA}

\section{Resumen}

Se trata de una investigación cualitativa de naturaleza fenomenológica realizada con 05 ancianos en proceso de alfabetización que procuró identificar prácticas curriculares exitosas, vinculadas al trabajo pedagógico que considera la Diversidad Religiosa en el desarrollo de la oralidad, de la escritura y la lectura. El trabajo reafirma la importancia de la temática Diversidad Religiosa en todos sus componentes curriculares, niveles y modalidades de la Educación Básica.

Palabras clave: Alfabetización de ancianos, Diversidad religiosa, Lectura y escritura

Lourival José Martins Filho

lourivalfaed@gmail.com 


\section{PONTOS DE PARTIDA}

A minha dedicação à alfabetização de jovens, adultos e idosos e, consequentemente pela temática deste artigo, nasceu na infância, na tranquila cidade de Laguna, litoral sul catarinense.

Tendo nascido de uma família pobre, comecei a compreender que, no mundo, qualquer que seja a atividade exercida, será no encontro com o "outro", na abertura para o diálogo, que encontraremos subsídios para nossa existência. Ao tentar compreender este mundo, bem como ao possibilitar ao outro que também melhor nos compreenda, estaremos ampliando nosso espaço como gente e como profissionais da Educação.

Registro então que minha mãe, para dar conta da renda familiar, cuidava de idosos. De todas as pessoas, idosos que minha mãe cuidou, a que me chamou mais atenção foi Rosa, a quem carinhosamente chamávamos de Rosinha.

Rosinha, na ocasião em que veio morar conosco, já estava com 97 anos. Lúcida, feliz, ela fazia com que a família sentasse ao seu redor para contar histórias (reais ou místicas). Eram histórias com precisão de detalhes pela emoção vivida.

Com 7 anos de idade eu ficava maravilhado ao ouvir Rosinha falar da guerra, dos bandeirantes, das casinhas escuras enquanto aviões aterrorizadores passavam pelo céu. Encantava-nos também ao falar sobre a sereia que aparecia uma vez por ano e acabava levando um pescador embora.

Nessa época, era preciso que brigassem comigo, porque eu preferia escu- tar as histórias de Rosinha a ter que ir frequentar a escola, na ocasião, com as famosas lições das cartilhas como "O cachorro bebe leite na cuia". Nada contra as cartilhas, mas os textos de Rosinha eram bem mais motivadores.

Já o gosto epistemológico pelo trabalho com a Diversidade Religiosa no contexto da Educação Básica é decorrente inicialmente de minha atuação como orientador educacional nas redes de ensino de Santa Catarina.

No diálogo com educadores e educadoras da educação básica e superior aprendemos que a ação e a reflexão são constituintes inseparáveis do fazer educativo. Ao pesquisarmos a Diversidade Religiosa nos anos iniciais do ensino fundamental, compartilhamos que a práxis é esse "que fazer" dos seres humanos sobre o mundo na perspectiva de transformá-lo”. (Freire 1998: 38).

Neste caminhar com o outro buscamos, sempre coletivamente, refletir, construir e reinventar outros cenários para a Diversidade Religiosa, especialmente com ênfase nos anos iniciais do ensino fundamental e consequentemente nos processos de alfabetização e letramento. Paulo Freire ensinou que não podemos renunciar à luta pelo exercício de nossa capacidade e de nosso direito de decidir e de romper, sem o que não reinventamos o mundo. Viver é possibilidade e não determinismo (Freire 2005: 23).

Entendemos neste trabalho a Diversidade Religiosa como parte da construção da sociedade. Tem em seu movimento diferentes manifestações culturais que fluem com a economia, 
as festividades, os hábitos alimentares, etc. Nesse sentido, as religiões, a crença e a não crença no sagrado, são parte da cultura humana, estão presentes em todos os povos, em todas as épocas históricas; Registra-se que no caldeirão cultural que é o Brasil, um de seus ingredientes é a Diversidade Religiosa.

Nesse sentido, a partir de uma leitura de Cecchetti (2008), pode-se afirmar que uma das marcas expressivas da diversidade cultural brasileira se encontra no campo religioso, onde (con)vivem inúmeras crenças e tradições religiosas de matriz indígena, africana, oriental e semita, entre outras. Essa diversidade religiosa historicamente constituída por interações, imposições e hibridismos, constitui uma riqueza ímpar nas diversas culturas presentes em nosso país; entretanto, ao mesmo tempo, exige atenção e esforços conjuntos no sentido de erradicar conflitos e relações de poder geradas por grupos hegemônicos, que buscam produzir identidades e diferenças na intenção de manter privilégios, por meio de processos de normalização do outro e anulação das diferenças.

Então, foram as inquietações vivenciadas no contexto escolar, bem como a inserção na universidade na área do estágio supervisionado dos anos iniciais do ensino fundamental que impulsionaram nossa ida ao doutorado e, posteriormente, para o estágio pós-doutoral, visando construir o departamento de Pedagogia da Universidade do Estado de Santa Catarina (UDESC) como docente efetivo, na interface com a Diversidade Religiosa e sua realidade no currículo de educação básica.

\section{CAMINHOS DA PESQUISA}

Segundo Aranha e Martins (1993), a Fenomenologia surge no final do século XIX, tendo como um de seus principais pensadores Edmund Husserl. É de Husserl (citado por Luijpen 1973: 151) a frase: "Somos, pois, e não podíamos prescindir disso funcionários da humanidade em nosso filosofar".

Ainda de acordo com Aranha e Martins (1993) o postulado básico da Fenomenologia é a noção de intencionalidade; não há pura consciência separada do mundo, toda consciência é consciência de alguma coisa, como também, não há objeto em si, para a Fenomenologia o objeto só existe para um sujeito que lhe dá significado.

É com esta atitude que entendo a Fenomenologia ao mesmo tempo, enquanto filosofia e método que a pesquisa foi realizada com 05 (cinco) idosos em processo de alfabetização em turmas na região da Grande Florianópolis.

Thomaz (1995) nos alerta que a organização e a análise dos dados na pesquisa qualitativa é um processo complexo. É necessário que o pesquisador tenha uma visão global do objeto pesquisado e do contexto que o circunda, sem, entretanto, perder as peculiaridades que podem muitas vezes enriquecer a compreensão fenomenológica.

Neste caminhar foram selecionados intencionalmente 05 alunos em processo de alfabetização, idosos com mais de 65 anos. Destes 05 participantes, 01 reside Florianópolis, 01 em São José, 01 em Santo Amaro da Imperatriz, 01 em Biguaçu e 01 em Palhoça. Todos os municípios mencionados pertencem 
à região da Grande Florianópolis em Santa Catarina; procuramos representar os principais municípios da região em questão.

Por uma questão ética e por solicitação dos idosos foi guardado o sigilo dos nomes dos educandos/idosos das suas respectivas professoras alfabetizadoras, bem como a escola em que estudam nas turmas de alfabetização.

As entrevistas foram realizadas no período noturno nas escolas em que eles estudavam na ocasião da pesquisa. Cada entrevista durou em torno de 60 minutos.

Todas as entrevistas ocorreram num clima de abertura. Os dados fluíram destas perguntas iniciais: colega, como você já sabe, estou realizando uma pesquisa e neste sentido a sua participação é fundamental. Gostaria que você falasse abertamente no tempo que desejar sobre: qual a sua avaliação sobre seu processo de aprendizagem na alfabetização?

Segundo Moraes (1993), pode-se descrever três momentos da investigação fenomenológica: o primeiro consiste num olhar atento para o fenômeno, procurando percebê-lo em sua totalidade; o segundo momento consiste em descrever o fenômeno, sem deixar-se levar pelas crenças e pré-conceitos e o último momento consiste em um mergulhamos nos aspectos essenciais do fenômeno.

A análise dos dados realizamos embasados em Giorgi (1985) que, conforme Metzler, Carpena e Borges (1994: 77), estruturou este procedimento investigativo nos seguintes passos:
- Fazer a leitura completa de cada descrição, para captar o sentido do todo. - Captar o sentido do todo e, então, voltar ao início para discriminar as unidades de significado, conforme uma determinada perspectiva (psicológica ou educacional) e com o foco no fenômeno que está sendo investigado.

- Delinear as unidades de significado, retomar todas as unidades, reescrevendo-as em função do fenômeno que está sendo investigado, ou seja, fazendo uma transformação das unidades de significado em linguagem educacional.

- Realizar a sintese de todas as unidades transformadas em uma perspectiva consistente relacioná-la com a experiência dos sujeitos.

Após a entrevista, a transcrição fiel dos depoimentos, o pesquisador, em reunião com os participantes, socializou de forma individual e coletiva as dimensões da pesquisa. Cada participante na ocasião apontou um nome fictício que gostaria de ser nomeado quando da sistematização e socialização dos dados.

O quadro dos nomes com o município de origem bem como idade por ocasião da socialização dos dados aos participantes ficou assim estabelecido

1 - Antônio - Florianópolis - 75 anos 2 - Laura - Santo Amaro da Imperatriz -81 anos

3 - Pedro - Biguaçu - 69 anos

4 - Maria - São José - 88 anos

5 - Fátima - Palhoça - 67 anos

É imperioso afirmar que não foi um caminho fácil, a reflexão fenomenológica exige um esforço contínuo.

Salientamos que os dados foram analisados num diálogo com a fenomeno- 
logia, bem como com a produção teórica atual relacionada à alfabetização, à Diversidade Religiosa e também ao componente curricular Ensino Religioso, integrante da matriz curricular da Educação Básica no Brasil.

Conforme Costa (1998), a descrição das falas, a apreensão do todo, a discriminação das unidades de significado desse todo, a interpretação dessas unidades a partir de meu olhar e a elaboração das estruturas de significados é um caminho que o rigor não pode ser excluído.

Assim, o movimento de ir vir aos dados possibilitou-me chegar as seguintes dimensões.

AS TRADIÇÕES RELIGIOSAS E SUAS PRÁTICAS DE LEITURA E ESCRITA COMO ELEMENTO CENTRAL NA BUSCA PELA APRENDIZAGEM DA LÍNGUA MATERNA POR IDOSOS

- Eu precisava participar com mais foco e carinho das missas. Quando eu li a primeira vez numa celebração um sentimento de alegria invadiu a minha alma. (Laura).

- Como eu ensinar o que eu acredito na minha fé se eu não sei ler e escrever. Como falar por e-mail sobre a minha religião se as letras me escapam. (Maria).

- Fui manipulado na vida por não saber escrever. Não me arrependo do que vivi. Me arrependo de não ter escrito mais coisas antes. Estou fazendo um livro de rimas e poesias. Não é para os outros lerem não... é pelo prazer de escrever Minhas rimas falam de minha fé, daquilo que eu acredito. (Antônio).

Os idosos em processo de alfabetização revelam que sentem o desejo de escrever, de pertencer à sociedade letrada. Estão inseridos em mundo cada vez mais globalizado onde as pessoas correm apressadamente na busca de novos conhecimentos.

Aprendemos com Bagno (2009) que escrita funda-se na vida. Assim, todas as produções textuais molham do contexto social onde estão inseridas.

Já Geraldi (1997) nos alerta que a escrita precisa ser viva, dinâmica e geradora de novas descobertas.

Nesse sentido, Faundez (1969) nos ensina que a alfabetização vai além de ser considerada como simples processo de aprendizagem da leitura e da escrita de uma língua determinada historicamente. A dimensão da alfabetização se ampliou, e hoje ela é quesito fundamental na permanente criação e recriação da sociedade. Os idosos revelam que não existe uma idade certa para o humano ser alfabetizado.

Fuck (1994) enfatiza o direito à aprendizagem em qualquer fase da vida. É perceptível que o desejo de escrever faz parte de pessoas inseridas em sociedades grafocêntricas.

Aprendemos com Merleau-Ponty (1973: 84) que "o mundo é inseparável do sujeito, mas de um sujeito que não é mais que o projeto do mundo, e o sujeito é inseparável do mundo, mas de um mundo que ele mesmo projeta."

Rezende (1990) nos adverte que nossa vida não tem apenas o sentido que outros lhe dão, mas aqueles que nós próprios lhe damos ou deixamos de dar. Um olhar atento a todas as entrevistas demonstra que os sujeitos participantes da pesquisa desejam conhecer, de- 
sejam apropriar-se do código escrito, desejam integrar-se à sociedade letrada, entender seus mecanismos, participar e intervir.

Já Haddad (1992) enfatiza que a Educação de Jovens e Adultos enquanto modalidade da Educação Básica é, sobretudo, um espaço de inclusão. Insira-se neste desafio uma alfabetização de idosos que possibilite a aprendizagem da apropriação do código escrito.

Esta questão também se envolve com o trabalho na Educação Básica com a temática Diversidade Religiosa, que pode contribuir no processo de alfabetização de idosos pela riqueza de textualidades, músicas e imagens, bem como pelo cotidiano em que os idosos estão encharcados. Entendemos que práticas curriculares que levem em conta a Diversidade Religiosa "não são um espaço reservado para a legitimação, a doutrinação ou a evangelização, de expressão de ritos, símbolos, campanhas e celebrações. Os conteúdos curriculares estão relacionados com as diversas manifestações do sagrado que constituem o conhecimento religioso, patrimônio cultural da humanidade." (Fuchs 2007: 133).

Registramos, porém, que é a partir das vivências que os idosos têm em sua vida diária com as suas tradições religiosas que a alfabetização encontra sentido. Para participar mais ativamente da sociedade letrada e informacional, em que o sagrado também se digitaliza, estar alfabetizado é fundamental. Assim temos em mente sempre que a escola "pode ser um espaço democrático pelo qual se expõe a diversidade de opiniões, afins e contraditórias, [...] sobre os mais variados temas que dizem respeito à dignidade humana". (Bobsin 2008: 14).

\section{A ALEGRIA DE LER TEXTOS, CONSI- DERADOS SAGRADOS, NA TERCEI- RA IDADE}

- Eu estava numa missa. E li pela primeira vez, a saudação inicial. Foi emocionante. Sempre pegava os folhetos e binários e não sabia ler e disfarçava que sabia, sabe. Hoje é uma alegria, eu posso ser chamado e ler na frente de todo mundo. (Antônio).

- Eu peguei o telefone, men caderno de receitas e li para uma vizinha. Ela ficou impressionada. Maria tu estás lendo. Agora além do meu caderno de receitas eu leio também a Bíblia. É uma sensação de liberdade. (Maria).

- Eu ficava impressionado quando mens colegas no trabalho liam jornais. Hoje eu tô velho, claro que tô, mas me sinto um menino quando consigo ler um jornal, as páginas policiais en leio num minuto. Eu também gosto de ler assuntos que envolvem religião. Meu passatempo é ler. (Pedro).

- Eu te digo que é uma alegria ler na terceira, eu penso, professor, que é uma alegria saber ler, não importa o tempo nem a idade. (Laura).

A fenomenologia nos ensina que ninguém pode responder com facilidade o que é conhecer, o que é saber. O que todos podemos é estar presentes como sujeitos cognoscentes na grande aventura do saber enquanto vivemos com o outro no mundo.

Para Luijpen (1973) o conhecimento não é algo entre duas realidades diver- 
sas, mas o próprio sujeito envolvido no mundo. Nesse movimento, encontro-me enquanto consciência engajada (Rezende 1990: 19).

Snyders (1993) alerta que somente se o aluno sentir alegria nas aprendizagens da escola é que poderá avançar em busca do que não conhece.

$\mathrm{Na}$ fala dos sujeitos, a alfabetização frutifica não apenas como domínio do código, mas como abertura e possibilidade de viver o mundo de forma mais enriquecedora por meio da leitura. Partimos da compreensão que leitura é entendida nesse contexto como um processo ativo, no qual o leitor idoso interage criando hipóteses, mobilizando seu conhecimento prévio em função de novos sentidos a cada oportunidade de leitura.

Soares (2001) aponta justamente a dimensão significativa que o letramento enquanto uso e intercâmbio social da língua materna pode oportunizar. Por isso, fica tão evidente a alegria da leitura do primeiro texto em função de todas as oportunidades posteriores a esta aprendizagem.

Aprendemos com Moll (1996) que uma alfabetização realmente comprometida gera no outro o gosto pelo saber, e por tudo que a relação leitura e escrita pode oportunizar.

Assim, alfabetizar alguém, além do compromisso ético, é despertar uma certa alegria e esperança pelo mundo que se abre pela possibilidade de ler, escrever, de conhecer, de crescer como gente.

[...] gente, miúda, jovem ou adulta, mas gente em permanente proces- so de busca. Gente firmando-se, mudando, crescendo, reorientando-se, melhorando, mas, porque gente, capaz de negar os valores, de distorcer-se, de recuar, de transgredir. Se não posso, de um lado, estimular os sonhos impossíveis, não devo, de outro, negar a quem sonha o direito de sonhar, lido com gente e não com coisas. (Freire 1997: 162).

Nesse contexto que a alfabetização se dá por meio do processo de textualização, aprendemos com Kleiman (1995) que ler então extrapola o mero decifrar de um código em busca de um sentido único. Os idosos nos revelam que ler é uma constante atuação do leitor sobre o texto. Esse entendimento só é viável numa linha de aprendizagem que tem por base a concepção interacional da língua, em que os sujeitos idosos são ativos e os sentidos construídos na interação texto-sujeitos. No âmbito do trabalho com a Diversidade Religiosa isso nos leva a refletir que ela traz uma contribuição significativa para a compreensão da religiosidade humana, do fenômeno religioso e de seus desafios. Assim, enfatizamos que uma alfabetização, quando é culturalmente significativa, intervém e potencializa de maneira favorável o próprio processo de formação humana dos idosos. Com isso a escola "passa a se ocupar com temas quentes sobre a vida humana, como aborto, reprodução humana, células tronco, igualdade racial e de gênero, métodos contraceptivos, Aids, entre outros". (Bobsin 2008: 15).

Nesta direção, partimos da compreensão que a Diversidade Religiosa pode ser trabalhada em todos os componen- 
tes curriculares da Educação Básica, isto porque o desenvolvimento em uma área do conhecimento diretamente afeta o desenvolvimento em outra área. A dinâmica interação de todas as áreas do conhecimento deve ser considerada, e o currículo deve ser desenvolvido e implantado de forma integrada.

\section{O PODER DA ESCRITA NAS DIFE- RENTES SITUAÇÕES DA VIDA}

- Tu vai achar até estranho, mas a relação com meus filhos e netos melhorou. Uso até Facebook. Divulgo um monte de coisa da minha igreja no face depois que me alfabetizei. (Fátima).

- Quando estou nas minhas filhas posso atender o telefone e anotar os recados com facilidade. Simples né. Não! Liberdade de não esperar para falar o que foi. Posso deixar por escrito. (Maria).

- Estou escrevendo poemas. Meus filhos estão ansiosos para lerem. Guardo a sete chaves. (Antônio).

- A minha familia contratou uma empregada. Com esta idade eles acham que eu não posso ficar mais sozinha. Eu deixo na geladeira por escrito o que deve fazer pro almoço e vou pro centro da cidade pra igreja. Pensa o que é isso? (Laura).

Rezende (1990: 84) vai nos afirmar que sendo o mundo cultural lugar de conflitos entre os homens, a educação terá como objeto a libertação de todas as formas de alienação, dominação e opressão.

Sob esse prisma quando pensamos em alfabetização entendemos como Rodrigues (1997) que esta não se restringe apenas a dotar os indivíduos de certas genialidades para ler e decodificar sím- bolos e letras. Ao se alfabetizarem, os indivíduos também se instrumentalizam para compreender e reconstruir a sua realidade.

Vale afirmar que o idoso em processo de alfabetização não é diferente de nenhum outro ser humano na luta por uma maior dignidade de vida. Ele quer sobreviver, participar, ter acesso aos bens que a sociedade já produziu, para isto, torna-se fundamental a procura pelo conhecimento sistematizado. Um saber escrever que sendo instrumentalizante deve oportunizar os limites como normalmente se faz, mas também as possibilidades geralmente esquecidas (Vasconcellos 1994).

Numa leitura de Braslavsky (1993) este ainda é um grande desafio que se coloca à escola contemporânea: alfabetizar com qualidade e competência

Já Cagliari (1998) desafia a nós professores alfabetizadores a busca pelo compromisso e rigor pedagógico e científico visando a aprendizagem daquele que se alfabetiza.

Necessitamos de práticas pedagógicas no processo de alfabetizar jovens adultos e idosos que levem em consideração o contexto social, cultural, religioso, geográfico, econômico e étnico no qual o currículo deve ser desenvolvido. Práticas curriculares que levem em consideração a Diversidade Religiosa para a práxis do currículo multicultural na educação brasileira, pois colabora para o "fortalecimento do diálogo, do respeito à diversidade, da solidariedade e da participação conjunta em busca da construção de uma sociedade humana e humanizadora.” (Silva 2000: 155). 
O professor alfabetizador de idosos precisa ter uma compreensão do processo educativo em sua complexidade, sem o que não poderá criar mediações que garantam o acesso do idoso ao mundo da cultura grafocêntrica.

Assim, as condições concretas de uma prática alfabetizadora precisam garantir ao professor o domínio de conteúdos humanizadores para garantir que seus alunos se apropriem das máximas qualidades humanas na construção de uma sociedade mais equânime inclusiva e solidária. Com isso o docente pode provocar o questionamento sobre o sentido da existência humana, tendo como especialidade essa capacidade de ir além da superfície dos acontecimentos, gestos ritos, normas formulações da fé, para interpretar a realidade e atuar na transformação da sociedade (Deon \& Bradenburg 2008: 150).

\section{CONSIDERAÇÕES FINAIS}

Nesse encaminhamento, pensando nos jovens adultos e idosos e minhas experiências nesta área, sinto, cada vez mais acentuada, a convicção que a alfabetização e o trabalho com a Diversidade Religiosa é compromisso de vida, abertura para o diálogo.

Acreditamos em educadores e escola que se expõem diante do risco de certezas abaladas da provisoriedade do saber, do contato com o outro, de olhares desejantes por descobertas, de palavras, frases e textos, é a preconizada por tantos outros pesquisadores na área de educação e ciência da(s) religião(ões) que estão abertos à transformação da sociedade.
E, nesse contexto, flui como emergente a necessidade de novas leituras, leituras críticas em que o novo é aceito, não enquanto imposto, mas assumido coletivamente. Essa escola que exige o risco de rejeição à hipocrisia das falas, dos discursos em prol da cidadania, mas que na prática desempregam, oprimem, excluem, fecham turmas de alfabetização de jovens, adultos e idosos com a audácia de afirmar que isto é inevitável.

Destacamos, porém, que é lastimável e assustadora a falta de compromisso das instituições formadoras com as discussões voltadas para a Diversidade Religiosa, como se esta dimensão fosse separada do humano em processo de aprendizagem. É preciso inserir essa discussão nos currículos de formação de professores de todas as licenciaturas. Nossa luta continuará na formação dos professores alfabetizadores que considerem a Diversidade Religiosa como uma das discussões fundamentais no processo de alfabetização e letramento.

Lá no fundo este trabalho reafirma o compromisso de uma educação inclusiva. Todos(as) têm o direito de "dizerem" as suas palavras. Compreender este mundo e reinventá-lo. Pensa o que é isso? - como afirmou Laura.

\section{REFERÊNCIAS}

Aranha, M. L. de A., e M. H. P. Martins. 1993. Filosofando introducão a filosofia. São Paulo: Moderna.

Bagno, M. 2009. Nada na língua é por acaso: por uma pedagogia da variação linguística. 3. ed. São Paulo: Parábola Editorial. 
Bobsin, O. 2008. Instituições religiosas e escola no espaço público. In Anais do $\mathrm{V}$ Simpósio de Ensino Religioso: $O$ ensino religioso: diversidade e identidade. Remi Klein, Laude Erandi Brandenburg, e Manfredo Carlos Wachs, orgs. Pp. 14-19. São Leopoldo: Sinodal/EST.

Braslavsky, B. 1993. Escola e alfabetização. São Paulo: UNESP.

Cagliari, L. C. 1998. Alfabetizando sem o ba-be-bi-bo-bu. São Paulo: Scipione.

Cecchetti, E. 2008. Diversidade cultural religiosa na cultura da escola. Dissertação de Mestrado em Educação, Universidade Federal de Santa Catarina (UFSC), Florianópolis (SC), Brasil.

Costa, M. T. A. 1998. O olhar do universitário como existência: o projeto de vida como desafio do III milênio. Dissertação de Mestrado em Educação, Pontifícia Universidade Católica do Rio Grande do Sul (PUC-RS), Porto Alegre (RS), Brasil.

Deon, J., e L. E. Bradenburg. 2008. O ensino religioso como área de conhecimento no ensino médio. In Anais do V Simpósio de Ensino Religioso: O ensino religioso: diversidade e identidade. Remi Klein, Laude Erandi Brandenburg, e Manfredo Carlos Wachs, orgs. Pp. 150-159. São Leopoldo: Sinodal/EST, 2008. São Leopoldo: Sinodal/EST.

Faundez, A. 1969. Oralidade e escrita. São Paulo: Paz e Terra.

Freire, P. 1997. Pedagogia da autonomia: saberes necessários a prática educativa. São Paulo: Paz e Terra.

1988. Pedagogia do oprimido. 18. ed. Rio de Janeiro: Paz e Terra.

2005. À sombra desta mangueira. São Paulo: Olho d'água.

Fuchs, H. L. 2007. Análise do material didático para o ensino religioso de Henri Luiz Fuchs. In Anais do IV Simpósio de Ensi- no Religioso: Práxis do ensino religioso na escola. Organizadores: Manfredo Carlos Wachs et al., orgs. Pp. 133-141. São Leopoldo: Sinodal/EST.

Fuck, I. T. 1994. Alfabetização de Adultos. Relato de uma experiência construtivista. 2. ed. Petrópolis: Vozes.

Geraldi, J. W. 1997. Portos de passagem. 4. ed. São Paulo: Martins Fontes.

Giorgi, A. 1985. Phenomenology and psychological research. Pittsburg: Dusquene University Press.

Haddad, S. 1992. Tendências atuais na educação de jovens e adultos. Mimeografado.

Kleiman, A. Org. 1995. Os significados do letramento. Campinas: Mercado das Letras.

Luijpen, W. A. M. 1973. Introdução à fenomenologia existencial. São Paulo: EPU.

Merleau-Ponty, M. 1973. Ciências do homem e fenomenologia. Tradução de Salma Tannus Muchail. São Paulo: Saraiva.

Metzler, A. M., L. B. Carpena, e R. M. R. Borges. 1994. Fenomenologia como filosofia e como método de investigação em pesquisas educacionais, in Paradigmas e metodologias de pesquisa em educação: notas para reflexão. M. E. Engers, org. Porto Alegre: EdiPUCRS.

Moll, J. 1996. Alfabetização possivel: reinventando o ensino e o aprender. Porto Alegre: Mediação.

Moraes, R. 1993. Fenomenologia: uma introdução. Educação 16(24):12-24.

Rezende, A. M. 1990. Concepscão fenomenológica da educação. São Paulo: Cortez.

Rodrigues, N. 1997. Por uma nova escola: o transitório e o permanente na educação. São Paulo: Cortez.

Silva, M. A. L. 2000. Viver, conviver. Poemas. Florianópolis. Mimeografado.

Snyders, G. 1993. Alunos felizes: reflexão sobre 
a alegria na escola a partir de textos literários. Rio de Janeiro: Paz e Terra.

Soares, M. 2001. Letramento: um tema em três gêneros. 2. ed. Belo Horizonte: Autêntica.

Thomaz, T. C. 1995. Significação do aprender matemática. Projeto de Dissertação de Mestrado em educação, Pontifícia Universidade Católica do Rio Grande do Sul (PUC-RS), Porto Alegre (RS), Brasil.

Vasconcellos, C. dos S. 1994. Disciplina: Construcão da disciplina consciente e interativa em sala de aula e na escola. 2. ed. São Paulo: Libertad (Cadernos Pedagógicos do Liber$\operatorname{tad})$. 